\title{
Prognostic factors influencing prognosis in early breast cancer patients
}

\author{
Safa Najafi ${ }^{1}$, Masoud Sadeghi ${ }^{2}$, Fereshteh Abasvandi ${ }^{1}$, Mohammad Reza Shajari ${ }^{1}$, Kamran Mohebi ${ }^{1}$, \\ Helen Ghandchi ${ }^{1}$
}

${ }^{1}$ Breast Diseases Department, Breast Cancer Research Centre, Motamed Cancer Institute, ACECR, Tehran, Iran

${ }^{2}$ Medical Biology Research Centre, Kermanshah University of Medical Sciences, Kermanshah, Iran

\begin{abstract}
Aim of the study: The present study showed the clinicopathological characteristics and survival of early breast cancer $(\mathrm{BC})$ patients.

Material and methods: A total of 236 patients were included in the study. The mean follow-up time was 59.5 months (range: 12-204 months). The inclusion criteria consisted of female patients aged $>20$ years and early BC patients (stages I and IIA).

Results: The mean age at diagnosis was 51.2 years (range, $23-83$ years), and $55.9 \%$ of patients were aged $\geq 50$ years. Most patients (92.8\%) did not have lymph node metastasis, and luminal B had the highest prevalence (54.2\%) in patients. The eight-year overall survival (OS) and disease-free survival (DFS) rates were $98.3 \%$ and $92.3 \%$, respectively. Stage IIA and Ki67 index $\geq 14 \%$ were more prevalent in the patients with tumour size of $2 \leq \mathrm{T} \leq 5 \mathrm{~cm}$ compared to another tumour size group and Ki67 index.

Conclusions: The mean age at diagnosis in this study was in agreement with other studies reported in various areas, but with a higher percentage for elderly patients compared to some previous studies. In addition, the survival rate in the present study was higher than the results of previous studies. Future studies need to investigate these factors in a higher number of patients and in different areas and should select similar stages for early BC.
\end{abstract}

Key words: early breast cancer, survival, recurrence, prognosis.

\section{Introduction}

Breast cancer (BC) is a heterogeneous disorder with different pathological and histological characteristics [1]. Based on the latest statistics from the International Agency for Research on Cancer (IARC), 1,677,000 women were diagnosed with $B C$ in 2012 and 577,000 died [2]. According to the American Cancer Society (ACS), around 252,710 BC deaths occurred in 2017 in the United States [3]. In Iranian women, BC mortality of 3.93 per 100,000 people in 2006 increased to 4.92 per 100,000 people in 2010 [4]. The global incidence of BC in women is predicted to be approximately 3.2 million new cases per year by 2050 [5].

$B C$ can be classified into different subtypes based on the diagnosis of oestrogen receptor (OR), progesterone receptor (PR), and human epidermal growth factor receptor 2 (HER2) [1]. Recurrence risk in BC changes during the follow-up time [6]. The prognosis of early $\mathrm{BC}$ depends on the patient and tumour characteristics [7]. Studies have reported that early BC detection with proper treatment can decrease $B C$ death rates signifi- cantly in the long term [8]. Early BCs can be fully resected by surgery [2]. A BC patient experiences $B C$ recurrence within 10 years following the achievement of initial treatment without adjuvant therapy $[2,9]$. There was no early $B C$ in Iran in the past due to the lack of screening studies. Nowadays, because of opportunistic screening and increasing of awareness of early BC among Iranian people, this study was performed to investigate the epidemiological features and survival of early BC (stages I and IIA), which is the first report in Iran.

\section{Material and methods}

This retrospective study was done on female patients referring to the Breast Cancer Research Centre, Tehran University of Medical Sciences, Tehran, Iran during 2008-2018. A total of 236 patients were included in the study. The clinicopathological factors (age at diagnosis, menopausal status, tumour size, lymph node metastasis, surgery, stage, grade, vascular invasion, lat- 
erality, OR, PR, HER2 status, Ki67 index, subtype, chemotherapy, and endocrine therapy) were obtained for each patient according to the pathological and clinical records. The mean follow-up period was 59.5 months (range: 12 to 204 months). The inclusion criteria consisted of: female patients aged > 20 years and early BC patients (stages I and IIA). The exclusion criteria included: male patients and patients without information about their OR, PR, or HER2 status. HER2 2+ detection by fluorescence in situ hybridisation (FISH) was considered HER2-positive. In addition, OR and PR were positive if staining was more than $10 \%$ of cells in the nucleus. Classification of tumours into four subtypes was done based on the study of Li et al. [10]. Overall survival (OS) was determined as the period from the date of $B C$ diagnosis to the date of death due to any reason, and disease-free survival (DFS) was determined as the period from the date of $\mathrm{BC}$ diagnosis to the first local/ regional recurrence, distant metastasis, or death due to any reason. The patients with tumour size greater than $1.2 \mathrm{~cm}$ were treated by chemotherapy because these patients had no lymph node metastasis. Chemotherapy regimens were AC4T4 (cyclophosphamide-adriamycin [AC]) used every three weeks for four cycles, followed by docetaxel (T) given every three weeks for four cycles, or anthracycline-based regimens and TC (docetaxel and cyclophosphamide) given every three weeks for four cycles, or non-anthracycline-based regimen. Anti-HER2 treatment was performed by trastuzumab in necessary cases for 17 sessions (one year) during or after chemotherapy. Hormone therapy regimens were aromatase inhibitors (letrozole and exemestane) or tamoxifen. In addition, in a number of patients, the tumour size was very small and the tumour was removed by excisional biopsy with a negative margin. Also, fine-needle aspiration (FNA) of axillary lymph nodes was negative; therefore, these patients did not undergo surgery. It is very common to use neoadjuvant chemotherapy to reduce the tumour size to make breast-conserving surgery possible in stage I-II breast cancer. Hence, many guidelines state that neoadjuvant chemotherapy should be used to reduce the size before surgery to make the surgeon more comfortable. All treatments (surgery, chemotherapy, and radiotherapy) were based on the National Comprehensive Cancer Network (NCCN) guidelines. Therefore, based on the NCCN, the size of the breast determines whether the patient requires neoadjuvant chemotherapy or not. When the size of the breast is small and even the size of the tumour is too small, it should be done first by neoadjuvant chemotherapy and then by breast-conserving surgery.

\section{Statistical analyses}

We used IBM SPSS (version 22) software (IBM Corp., Armonk, NY, USA) for the analysis of data. $\chi^{2}$ test was used for the analysis of differences between the variables. A $p$-value (two-tailed) $<0.05$ was considered statistically significant, with the confidence interval (CI) of $95 \%$. DFS and OS curves were plotted by GraphPad Prism software (package version 5.0; GraphPad Software Inc., San Diego, CA, USA). The probability of OS and DFS over time was performed by applying Kaplan-Meier curves, and the comparison of OS and DFS between the subtypes of $\mathrm{BC}$ was performed by log-rank analysis.

\section{Results}

The mean age at diagnosis was 51.2 years (range: 23-83 years), and $55.9 \%$ of patients were aged $\geq 50$ years. Table 1 shows the baseline characteristics of 236 patients with early BC. Tumour size was $2 \leq \mathrm{T} \leq 5 \mathrm{~cm}$ in $50.4 \%$ of patients and $<2 \mathrm{~cm}$ in $49.6 \%$ of patients (range: $0.1-5 \mathrm{~cm}$ ). Most patients $(92.8 \%)$ did not have lymph node metastasis. Out of all patients, 162 patients underwent surgery, 155 patients underwent chemotherapy, and 232 patients received endocrine therapy. Stages I and IIA were found in 128 and 108 patients, respectively; whereas, grades I, II, and III were observed in 45,148 , and 43 patients, respectively. Out of all patients checked for vascular invasion, 36 patients were positive. Laterality in 108 patients was found in the right side, and the rest of the patients were found to have laterality in the left side. The receptors showed that $80.1 \%$, $73.3 \%$, and $49.2 \%$ of patients were OR-, PR-, and HER2positive, respectively. Out of 165 patients checked for Ki67 index, $45.5 \%$ had an index of less than 14\%, with a mean of $20.7 \%$ in all patients. Most of the patients had tumours with luminal B (54.2\%), followed by luminal A (27.1\%) and HER2 overexpression (11\%), and just $7.6 \%$ had triple-negative tumours.

Figure 1 illustrates the OS and DFS of early BC patients. The eight-year OS rate and mean OS were $98.3 \%$ and 57.2 months, respectively. In addition, the eightyear DFS rate and mean DFS were $92.3 \%$ and 55.4 months, respectively.

The prevalence rates of age, tumour size, and Ki67 index are shown in Figure 2. Most of the patients were between the ages of 40 and 60 years, and the number of young and elderly patients was very low. In addition, most of the patients with early BC had a tumour size of 1 to $3 \mathrm{~cm}$, and the Ki67 index in most of the patients was $\leq 40 \%$.

Table 2 shows the clinicopathological features of the patients with early BC grouped by mean age. Among the variables, there was no significant difference for all variables with mean age group, except for menopausal status $(p<0.001)$.

The clinicopathological features of the patients with early BC grouped by tumour size are shown in Table 3. Stage and Ki67 index had a significant difference with 
Table 1. Characteristics of the patients with early breast cancer $(n=236)$

\begin{tabular}{|c|c|}
\hline Variable & Value \\
\hline $\begin{array}{l}\text { Age, } n(\%) \\
\text { Mean } \pm \text { SD (range) } \\
<50 \text { years } \\
\geq 50 \text { years }\end{array}$ & $\begin{array}{c}51.2 \pm 11.2(23-83) \\
104(44.1) \\
132(55.9) \\
\end{array}$ \\
\hline $\begin{array}{l}\text { Menopausal status, } n(\%) \\
\text { Premenopausal } \\
\text { Postmenopausal } \\
\end{array}$ & $\begin{array}{l}114(48.3) \\
122(51.7) \\
\end{array}$ \\
\hline $\begin{array}{l}\text { Tumour size, } n \text { (\%) } \\
\text { Mean } \pm \text { SD (range) } \\
<2 \mathrm{~cm} \\
2 \leq \mathrm{T} \leq 5 \mathrm{~cm}\end{array}$ & $\begin{array}{c}1.85 \pm 0.69(0.1-5) \\
117(49.6) \\
119(50.4)\end{array}$ \\
\hline $\begin{array}{l}\text { Lymph node metastasis, } n \text { (\% } \\
\text { Yes } \\
\text { No }\end{array}$ & $\begin{array}{c}17(7.2) \\
219(92.8) \\
\end{array}$ \\
\hline $\begin{array}{l}\text { Surgery, } n(\%) \\
\text { Breast-conserving surgery } \\
\text { Mastectomy } \\
\text { No }\end{array}$ & $\begin{array}{l}99(41.9) \\
63(26.7) \\
74(31.4) \\
\end{array}$ \\
\hline $\begin{array}{l}\text { Stage, } n(\%) \\
\text { I } \\
\text { IIA }\end{array}$ & $\begin{array}{l}128(54.2) \\
108(45.8)\end{array}$ \\
\hline $\begin{array}{l}\text { Grade, } n(\%) \\
\text { I } \\
\text { II } \\
\text { III } \\
\end{array}$ & $\begin{array}{c}45(19.1) \\
148(62.7) \\
43(18.2) \\
\end{array}$ \\
\hline $\begin{array}{l}\text { Vascular invasion, } n(\%) \\
\text { Positive } \\
\text { Negative }\end{array}$ & $\begin{array}{c}36(15.3) \\
200(84.7) \\
\end{array}$ \\
\hline $\begin{array}{l}\text { Laterality, } n(\%) \\
\text { Right } \\
\text { Left }\end{array}$ & $\begin{array}{l}108(45.8) \\
128(54.2) \\
\end{array}$ \\
\hline $\begin{array}{l}\text { OR, } n(\%) \\
\text { Positive } \\
\text { Negative }\end{array}$ & $\begin{array}{c}189(80.1) \\
47(19.9)\end{array}$ \\
\hline $\begin{array}{l}\text { PR, } n(\%) \\
\text { Positive } \\
\text { Negative } \\
\end{array}$ & $\begin{array}{c}173(73.3) \\
63(26.7) \\
\end{array}$ \\
\hline $\begin{array}{l}\text { HER2, } n(\%) \\
\text { Positive } \\
\text { Negative }\end{array}$ & $\begin{array}{l}116(49.2) \\
120(50.8)\end{array}$ \\
\hline $\begin{array}{l}\text { Ki67, } n(\%)(n=165) \\
\text { Mean } \pm \text { SD (range) } \\
<14 \\
\geq 14\end{array}$ & $\begin{array}{c}20.7 \pm 17.2(0-90) \\
75(45.5) \\
90(54.5) \\
\end{array}$ \\
\hline $\begin{array}{l}\text { Subtype, } n(\%) \\
\text { Luminal A } \\
\text { Luminal B } \\
\text { HER2 overexpression } \\
\text { Triple-negative }\end{array}$ & $\begin{array}{c}64(27.1) \\
128(54.2) \\
26(11) \\
18(7.6)\end{array}$ \\
\hline $\begin{array}{l}\text { Chemotherapy, } n(\%) \\
\text { Yes } \\
\text { No }\end{array}$ & $\begin{array}{c}155(65.7) \\
81(34.3) \\
\end{array}$ \\
\hline $\begin{array}{l}\text { Endocrine therapy, } n(\%) \\
\text { Yes } \\
\text { No }\end{array}$ & $\begin{array}{c}232(98.3) \\
4(1.7)\end{array}$ \\
\hline
\end{tabular}

tor, PR - progesterone receptor, SD - standard deviation tumour size groups $(p<0.001$ and $p=0.006$, respectively). Stage IIA and Ki67 index $\geq 14 \%$ were higher in the patients with tumour size of $2 \leq \mathrm{T} \leq 5 \mathrm{~cm}$ compared to another tumour size group and Ki67 index.

Figure 3 shows the comparison of eight-year OS and DFS of the early BC patients based on molecular subtype. The OS rates were $98.4 \%, 98.4 \%, 96.2 \%$, and $100 \%(p=0.814)$ and DFS rates were $93.8 \%, 94.5 \%$, $80.8 \%$, and $88.9 \%(p=0.108)$ in luminal A, luminal B, HER2 overexpression, and triple-negative groups, respectively. In pairwise comparison, the difference in OS and DFS rates between both subtypes was not significant: luminal A vs. luminal B, luminal A vs. HER2 overexpression, luminal A vs. triple-negative, luminal B vs. HER2 overexpression, luminal B vs. triple-negative, and HER2 overexpression vs. triple-negative.

\section{Discussion}

As in Iran, due to the onset of BC at an early age, early warning and screening programs are essential for early diagnosis despite the relatively high levels of survival compared to other cancers [11]. One study indicated that age-standardised incidence rates of BC in Central and Northern provinces of Iran were higher than elsewhere [12]. The present study evaluated some characteristics, including OS and DFS of the early BC patients (stages I and IIA) and correlation between the factors associated with it.

Based on NCCN guidelines, the size of the breast determines whether the patient needs neoadjuvant chemotherapy or not. When the size of the breast is small and even the size of the tumour is too small, it should be done first by the neoadjuvant chemotherapy and then by breast-conserving surgery. Out of 6248 early BC patients treated in neoadjuvant and adjuvant chemotherapy in a cohort, $57 \%$ showed OR positivity, 43\% PR positivity, 17\% HER2 positivity, 20\% triple-negative, and $35 \%<2 \mathrm{~cm}$ in tumour size [13]. In addition, another study on 1287 early BC patients in China (stage I-III) reported that $44.6 \%, 44.6 \%, 55.8 \%, 17.7 \%$, and $23.5 \%$ of patients had tumour size $<2 \mathrm{~cm}$, lymph node metastasis, grade III, triple-negative, and Ki67 < 14\%, respectively [10]. The prevalence of these variables in the present study (stage I and IIA) was $49.6 \%, 7.2 \%$, $18.2 \%, 80.1 \%, 73.3 \%, 49.2 \%, 45.5 \%$, and $7.6 \%$ for tumour size $<2 \mathrm{~cm}$, lymph node metastasis, grade III, OR positivity, PR positivity, HER2 positivity, Ki67 < 14\%, and triple-negative, respectively. These differences can be due to the selection of different stages for early BC among studies.

The mean age at diagnosis in our study on $\mathrm{BC}$ patients with stages I and II was 51.2 years $(55.9 \%$ had age $\geq 50$ years), as in previous Iranian studies: 47.6 years [14] and 49.6 years [15]. Three studies [10, 16, 17] reported early BC patients (stages I to III or stages I 

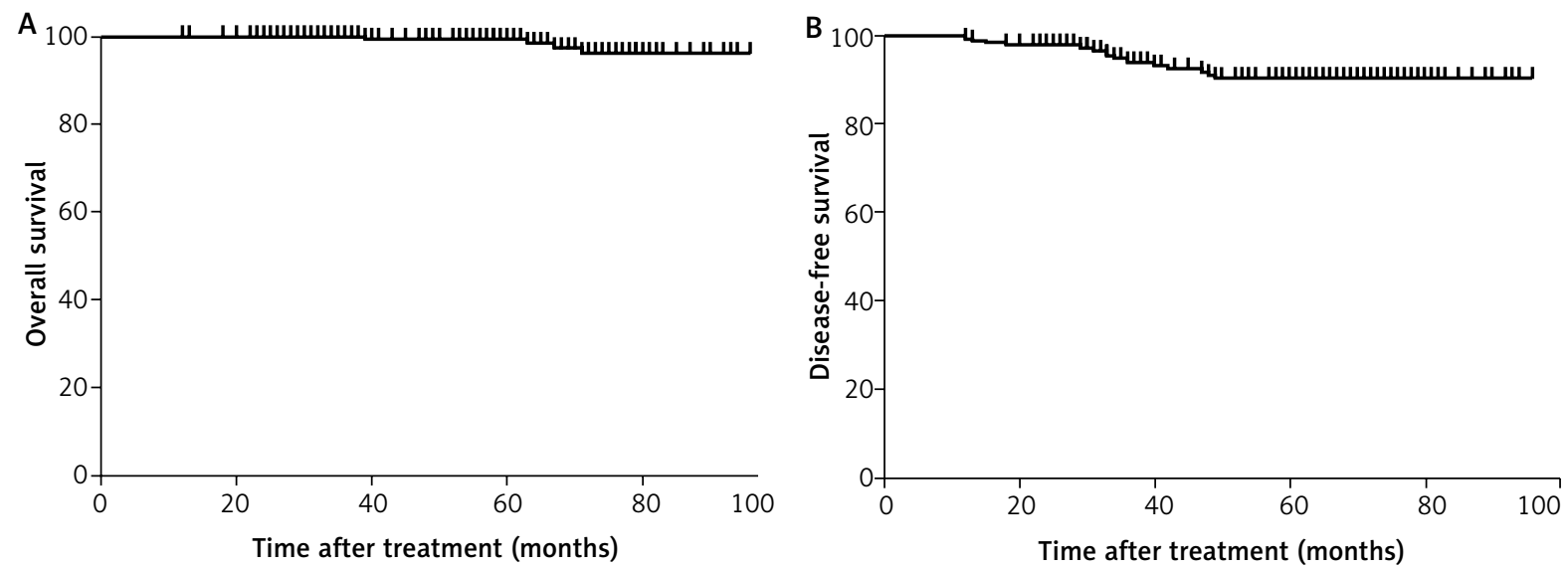

Fig. 1. The 8-year (A) overall survival and (B) disease-free survival in the early breast cancer patients
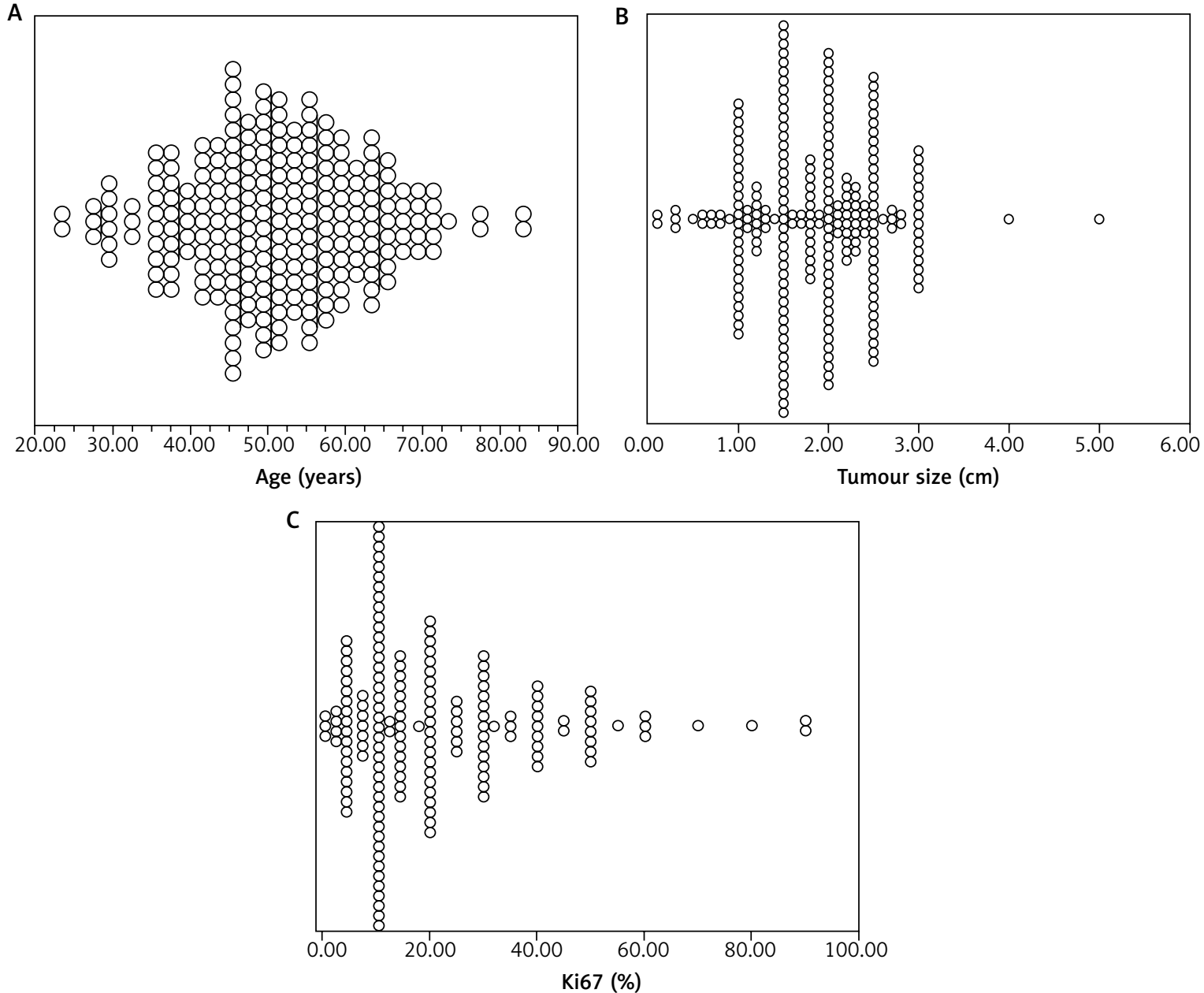

Fig. 2. The distribution of (A) age, (B) tumour size, and (C) Ki67 index in the patients with early breast cancer

and III), one study reported the median age of 50 years at diagnosis (age range: $42-59$ years; $51.2 \% \geq 50$ years), another study reported the mean age of 48.2 years, and the last study reported the median age of 51 years (range: 28-92 years). One study [18] selected 36,340 Iranian women and reported the highest age-specific incidence rate (ASIR) for the age ranges 45-65 and
80-85 years, respectively. Therefore, almost mean age of $B C$ patents in different areas is similar, but with a different percentage of elderly patients among studies.

Among Iranian women, $\mathrm{BC}$ is the third most common cause of death, and age at onset of $B C$ has decreased from 40.0 to 30.0 years [19]. Of the 1500 Iranian $\mathrm{BC}$ patients, $36 \%$ had age $\geq 50$ years, and the result 
Table 2. Clinicopathological features of the patients with early breast cancer grouped by age at diagnosis $(n=236)$

\begin{tabular}{|c|c|c|c|}
\hline Variable & $<50$ years & $\geq 50$ years & $p$-value \\
\hline Menopausal status, $n(\%)$ & & & $<0.001$ \\
\hline Premenopausal & $104(100)$ & $10(7.6)$ & \\
\hline Postmenopausal & $0(0)$ & $122(92.4)$ & \\
\hline Tumour size, $n(\%)$ & & & 0.241 \\
\hline$<2 \mathrm{~cm}$ & $47(45.2)$ & $70(56.0)$ & \\
\hline $2 \leq \mathrm{T} \leq 5 \mathrm{~cm}$ & $57(54.8)$ & $63(47.0)$ & \\
\hline $\begin{array}{l}\text { Lymph node metastasis, } \\
n(\%)\end{array}$ & & & 0.126 \\
\hline Yes & $4(3.8)$ & $13(9.8)$ & \\
\hline No & $100(96.2)$ & $119(90.2)$ & \\
\hline Stage, $n(\%)$ & & & 0.599 \\
\hline 1 & $54(51.9)$ & $74(56.1)$ & \\
\hline IIA & $50(48.1)$ & $58(43.9)$ & \\
\hline Grade, $n(\%)$ & & & 0.057 \\
\hline I & $18(17.3)$ & $27(20.5)$ & \\
\hline ॥ & $60(57.7)$ & $88(66.7)$ & \\
\hline III & $26(25.0)$ & $17(12.9)$ & \\
\hline Vascular invasion, $n(\%)$ & & & 0.365 \\
\hline Positive & $13(12.5)$ & $23(17.4)$ & \\
\hline Negative & $91(87.5)$ & $109(82.6)$ & \\
\hline Laterality, $n$ (\%) & & & 0.360 \\
\hline Right & $44(42.3)$ & $64(48.5)$ & \\
\hline Left & $60(57.7)$ & $68(51.5)$ & \\
\hline Ki67, $n(\%)(n=165)$ & & & 0.492 \\
\hline Mean \pm SD & $21.8 \pm 17.1$ & $19.9 \pm 17.3$ & \\
\hline$<14$ & $30(41.7)$ & $45(48.4)$ & \\
\hline$\geq 14$ & $42(58.3)$ & $48(51.6)$ & \\
\hline
\end{tabular}

showed a low number of elderly women with BC in Iran [20]. A nested cohort on 6248 early BC patients was in agreement with this research [13], whereas a cohort of

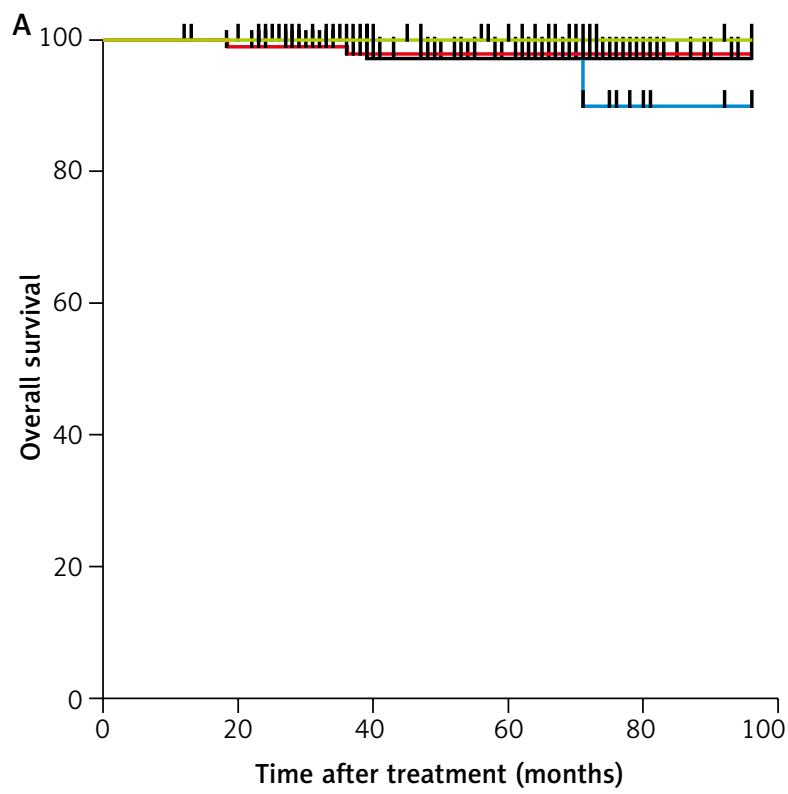

Table 3. Clinicopathological features of the patients with early breast cancer grouped by tumour size $(n=236)$

\begin{tabular}{lccc}
\hline Variable & $<2 \mathrm{~cm}$ & $2 \leq \mathbf{T} \leq \mathbf{5} \mathrm{cm}$ & $p$-value \\
\hline $\begin{array}{l}\text { Menopausal status } \\
\text { Premenopausal }\end{array}$ & $53(45.3)$ & $61(51.3)$ & 0.366 \\
Postmenopausal & $64(54.7)$ & $58(48.7)$ & \\
\hline Lymph node metastasis & & & 0.515 \\
Yes & $8(6.8)$ & $9(7.6)$ & \\
No & $109(93.2)$ & $110(92.4)$ & \\
\hline Stage & & & $<0.001$ \\
I & $117(100)$ & $11(9.2)$ & \\
IIA & $0(0)$ & $108(90.8)$ & \\
\hline Grade & & & 0.197 \\
I & $23(19.7)$ & $22(18.5)$ & \\
II & $78(66.7)$ & $70(58.8)$ & \\
III & $16(13.7)$ & $27(22.7)$ & \\
\hline Vascular invasion & & & 0.113 \\
Positive & $14(12)$ & $22(18.5)$ & \\
Negative & $103(88)$ & $97(81.5)$ & \\
\hline Laterality & & & 0.151 \\
$\quad$ Right & $58(49.6)$ & $50(42)$ & \\
Left & $59(50.4)$ & $699(58)$ & \\
\hline Ki67, \% $(n=165)$ & & & 0.006 \\
Mean \pm SD & $17.7 \pm 15.1$ & $24.3 \pm 18.8$ & \\
$<14$ & $49(55.1)$ & $26(34.2)$ & \\
$\geq 14$ & $40(44.9)$ & $50(65.8)$ & \\
\hline
\end{tabular}

767 Brazilian BC patients showed the opposite results [21]. The percentage of elderly patients ( $\geq 50$ years) in the present study was $55.9 \%$. Many studies have reported that elderly women ( $\geq 70$ years of age) have less aggressive $B C$, including a higher frequency of lower grade tumours and positivity for hormone receptor [22,

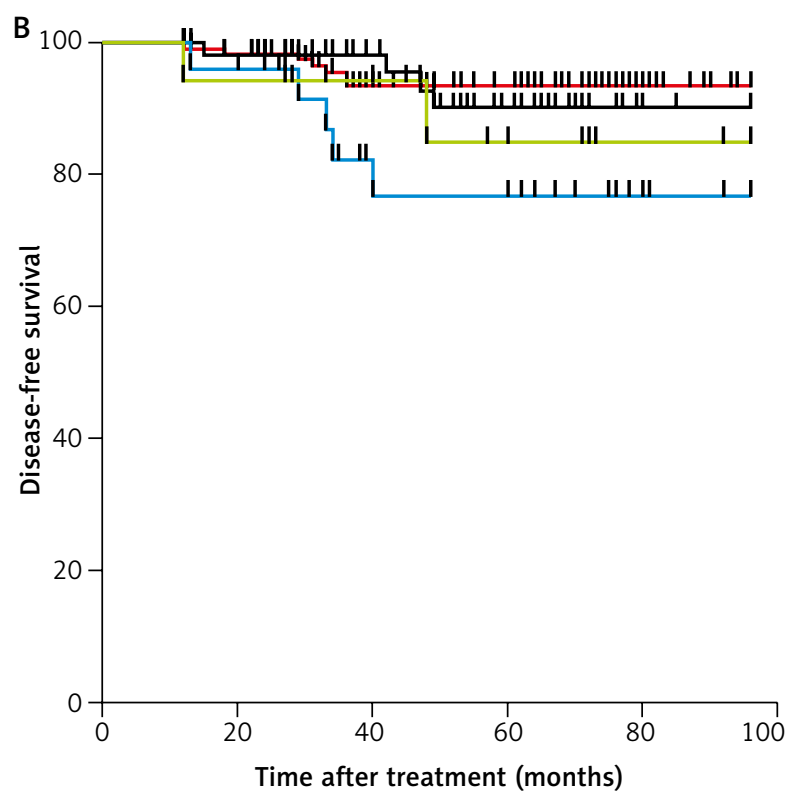

$\perp$ Luminal A Luminal B $\perp$ HER2 overexpression $\perp$ Triple negative molecular subtype 
23]. In the present study, there was no significant difference between $B C$ patients $\geq 50$ years old compared to $<50$ years old in terms of menopausal status, tumour size, lymph node metastasis, stage, grade, vascular invasion, laterality, and Ki67 index.

Much attention has been paid to small tumours in recent years, because T1a, bN0 tumours generally present with a good prognosis [10]. In particular, a patient with a tumour size of $2.1 \mathrm{~cm}$ can have a different prognosis than a patient with a 4.9-cm tumour [24]. A study [5] reported no correlation between the tumour size and Ki67 index (cut-off: 20\%). In this study, large tumour size was significantly correlated with more advanced stage and Ki67 index (cut-off: 14\%), and the difference in the results of Ki67 can be due to different cut-offs. However, the difference between two tumour size groups was not significant in other variables, but there was a lower lymph node metastasis, vascular invasion, and grade in the patients with small tumours.

In early BC patients with a median follow-up of 8.4 years, $5 \%$ of all patients had a local recurrence, whereas $28 \%$ had progressive metastasis [17]. The present study showed that the eight-year OS and DFS rates were $98.3 \%$ and $92.3 \%$, respectively. A meta-analysis found that the one-, three-, five-, and 10-year OS rates of $\mathrm{BC}$ in Iran were estimated to be $95.8 \%, 82.4 \%$, $69.5 \%$, and $58.1 \%$, respectively [25]. A study [17] on early $\mathrm{BC}$ patients indicated that OS rates at ages 5,10 , 15,20 , and 25 years were $82 \%, 62 \%, 49 \%, 39 \%$, and $28 \%$, respectively. A study on early $\mathrm{BC}$ with a median follow-up of 33 months showed the three- and five-year OS rates were $95.0 \%$ and $90.8 \%$, respectively [10]. The mean five-year OS rate of women with BC was $71 \%$ in Iran in 2007 [26] compared to $92 \%$ in the United States [27]. In a cohort study including 1249 early BC patients (stages I to III) with a median follow-up of 73.7 months, there were 344 events (27.5\%), including 272 cases with distant relapse, 64 cases with locoregional recurrence, and eight cases with contralateral neoplasms [6]. The results of one study showed that age, major diameter, tumoural volume, grading, and molecular subtype influenced DFS in univariate analysis [7]. The OS and DFS in the present study were better than in other studies including early breast cancer patients. This difference can be due to selecting different stages for early $\mathrm{BC}$ in the studies. Future studies should pay attention to selecting similar criteria for early stage of $B C$ to obtain stronger and more accurate conclusion about early BC patients.

One research [28] included women aged $>65$ years at $B C$ diagnosis and found more early-stage neoplasms in the luminal subtypes. A study of 1287 early BC (stages I-III) patients [10] showed the five-year OS rate was $97.3 \%$ in luminal $A, 94.1 \%$ in luminal $\mathrm{B}, 67.6 \%$ in HER2 overexpression, and $66.5 \%$ in triple-negative tumour $(p<0.001)$, which is in disagreement with the results of the present research (stages I and II). The difference between these two studies can be due to the selection manner of the early BC patients.

\section{Conclusions}

The present retrospective study investigated the clinicopathological features and survival of early BC patients, reflecting the situation of diagnosis and treatment in an area of Iran. The mean age at diagnosis in this study was in agreement with other studies reported in various areas, but with a higher percentage for elderly patients compared to some previous studies. In addition, the survival rate in the present study was higher than the results of previous studies. These differences can be due to the selection of different stages for early BC, which must be carefully considered in future research. Future studies need to investigate these factors in a higher number of patients and different areas, selecting similar criteria for early BC.

\section{Disclosure}

The authors report no conflict of interest.

\section{References}

1. Payandeh M, Sadeghi M, Sadeghi E, Madani SH. Expression of p53 breast cancer in kurdish women in the west of Iran: a reverse correlation with lymph node metastasis. Asian Pac J Cancer Prev 2016; 17: 1261-1264.

2. Miller E, Lee HJ, Lulla A, et al. Current treatment of early breast cancer: adjuvant and neoadjuvant therapy. F1000Res 2014; 3: 198.

3. U.S. Breast Cancer Statistics 2017. http://www.breastcancer.org/symptoms/understand_bc/statistics (accessed: 2 July 2017)

4. Enayatrad M, Amoori N, Salehiniya H. Epidemiology and trends in breast cancer mortality in iran. Iran J Public Health 2015; 44: 430-431.

5. Tao Z, Shi A, Lu C, et al. Breast Cancer: Epidemiology and Etiology. Cell Biochem Biophys 2015; 72: 333-338.

6. Ribelles N, Perez-Villa L, Jerez JM, et al. Pattern of recurrence of early breast cancer is different according to intrinsic subtype and proliferation index. Breast Cancer Res 2013; 15: R98.

7. Kasangian AA, Gherardi G, Biagioli E, et al. The prognostic role of tumor size in early breast cancer in the era of molecular biology. PLoS One 2017; 12: e0189127.

8. Migowski A. Early detection of breast cancer and the interpretation of results of survival studies. Cienc Saude Coletiva 2015; 20: 1309.

9. Voduc KD, Cheang MC, Tyldesley S, et al. Breast cancer subtypes and the risk of local and regional relapse. J Clin Oncol 2010; 28: 1684-1691.

10. Li S, Wang X, Yang J, et al. Clinicopathological features and survival of early stage breast cancer in northwest China: A population-based retrospective study of 1287 patients. Thorac Cancer 2018; 9: 10-18.

11. Rahimzadeh M, Pourhoseingholi MA, Kavehie B. Survival Rates for Breast Cancer in Iranian Patients: a Meta- Analysis. Asian Pac J Cancer Prev 2016; 17: 2223-2227.

12. Shadmani F, Mansori K, Khazaei S, et al. Geographic distribution of breast cancer incidence in Iran. Biomed Res Ther 2017; 4: 1295-1304.

13. Abraham JE, Hiller L, Dorling L, et al. A nested cohort study of 6,248 early breast cancer patients treated in neoadjuvant and adjuvant chemotherapy trials investigating the prognostic value of chemotherapy-related toxicities. BMC Med 2015; 13: 306. 
14. Madani SH, Payandeh M, Sadeghi M, et al. The correlation between Ki67 with other prognostic factors in breast cancer: A study in Iranian patients. Indian J Med Paediatr Oncol 2016; 37: 95-99.

15. Jazayeri SB, Saadat S, Ramezani R, Kaviani A. Incidence of primary breast cancer in Iran: Ten-year national cancer registry data report. Cancer Epidemiol 2015; 39: 519-527.

16. Yang J, Tang S, Zhou Y, et al. Prognostic implication of the primary tumor location in early-stage breast cancer: focus on lower inner zone. Breast Cancer 2018; 25: 100-107.

17. Iturbe J, Zwenger A, Leone JP, et al. Treatment of early breast cancer, a long-term follow-up study: the GOCS experience. Breast J 2011; 17: 630-637.

18. Rafiemanesh H, Salehiniya H, Lotfi Z. Breast Cancer in Iranian Woman: Incidence by Age Group, Morphology and Trends. Asian Pac J Cancer Prev 2016; 17: 1393-1397.

19. Vahid F, Hatami M, Sadeghi M, et al. The association between the Index of Nutritional Quality (INQ) and breast cancer and the evaluation of nutrient intake of breast cancer patients:A case-control study. Nutr J 2018; 45: 11-16.

20. Vostakolaei FA, Broeders MJM, Rostami N, et al. Age at Diagnosis and Breast Cancer Survival in Iran. Int J Breast Cancer 2012; 2012: 517976.

21. Balabram D, Turra CM, Gobbi H. Association between age and survival in a cohort of Brazilian patients with operable breast cancer. Cad Saude Publica 2015; 31: 1732-1742.

22. Schonberg MA, Marcantonio ER, Ngo L, et al. Causes of death and relative survival of older women after a breast cancer diagnosis. J Clin Oncol 2011; 29: 1570-1577.

23. Dutra MC, Rezende MA, de Andrade VP, et al. Imunofenótipo e evolução de câncer de mama: comparação entre mulheres muito jovens e mulheres na pós-menopausa. Rev Bras Ginecol Obstet 2009; 31: 54-60.

24. Veronesi U, Zurrida S, Viale G, et al. Rethinking TNM: a breast cancer classification to guide to treatment and facilitate research. Breast J 2009; 15: 291-295.

25. Abedi G, Janbabai G, Moosazadeh M, et al. Survival Rate of Breast Cancer in Iran: A Meta-Analysis. Asian Pac J Cancer Prev 2016; 17: 46154621.

26. Mousavi SM, Montazeri A, Mohagheghi MA, et al. Breast cancer in Iran: an epidemiological review. Breast J 2007; 13: 383-391.

27. Hunt KK, Robertson JFR, Bland KI. The Breast. In: Schwartz Principles of Surgery, $10^{\text {th }}$ ed., Brunicardi FC, Andersen DK, Billiar TR, et al. McGrawHill, New York 2015.

28. Engels CC, Kiderlen M, Bastiaannet E, et al. The clinical prognostic value of molecular intrinsic tumor subtypes in older breast cancer patients: A FOCUS study analysis. Mol Oncol 2016; 10: 594-600. 